Supporting information ol061993u -2

\title{
Intermolecular Tandem Addition-Cyclization Reaction of Bromoallenes: A Facile Synthesis of Methylenecyclopropyl Carboxylates and Polysubstituted Furans
}

\author{
Lubin $\mathrm{Xu}^{\mathrm{a}}$, Xian Huang*a,b and Fangrui Zhong ${ }^{\mathrm{a}}$ \\ ${ }^{a}$ Department of Chemistry, Zhejiang University (Xixi Campus), Hangzhou 310028, P. R. \\ China \\ ${ }^{b}$ State Key Laboratory of Organometallic Chemistry, Shanghai Institute of Organic \\ Chemistry, Chinese Academy of Sciences, Shanghai 200032, P. R. China \\ Fax:+86(571)88807077; E-Mail: huangx@mail.hz.zj.cn
}

Supporting information-2

\section{Table of Contents}

1. Analytical data of dimethyl 2-(non-1-yn-3-yl)malonate S2

2. ${ }^{1} \mathrm{H}$ NMR and ${ }^{13} \mathrm{C}$ NMR spectra of dimethyl 2-(non-1-yn3-yl)malonate. S3 


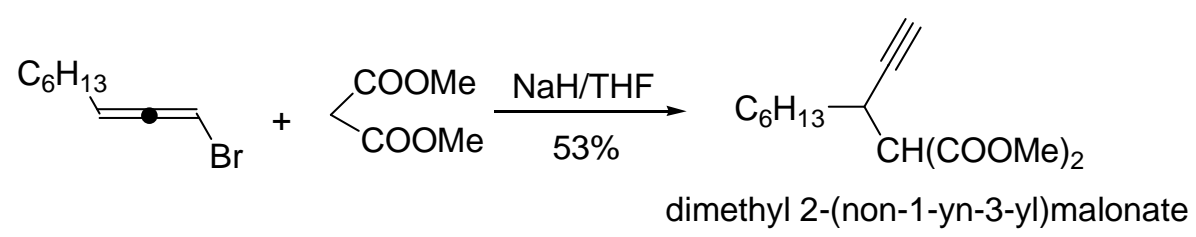

Dimethyl 2-(non-1-yn-3-yl)malonate :

Oil. ${ }^{1} \mathrm{H}$ NMR (400 MHz, $\left.\mathrm{CDCl}_{3}\right): \delta 3.75$ (d, $\left.J=4 \mathrm{~Hz}, 6 \mathrm{H}\right), 3.49$ (d, $J=9.2$ Hz, $1 \mathrm{H}), 3.17-3.12(\mathrm{~m}, 1 \mathrm{H}), 2.12(\mathrm{~d}, J=2.0 \mathrm{~Hz}, 1 \mathrm{H}), 1.58-1.43(\mathrm{~m}, 4 \mathrm{H})$, 1.42-1.25 (m, $6 \mathrm{H}), 0.88(\mathrm{~m}, 3 \mathrm{H}) .{ }^{13} \mathrm{C}$ NMR $\left(100 \mathrm{MHz}, \mathrm{CDCl}_{3}\right) \delta 167.7$ (d, $J=6.8 \mathrm{~Hz}$ ), 83.3, 71.1, 56.1, 52.6 (d, $J=4.5 \mathrm{~Hz}), 32.3,31.6,31.5,28.7,26.8$, 22.5, 13.9. IR (neat): 3304, 1740. MS (EI): $m / z(\%) 255\left(\mathrm{M}^{+}+1,100\right), 169$ (97.5). Anal.Calcd.for $\mathrm{C}_{14} \mathrm{H}_{22} \mathrm{O}_{4}$ : C, 66.12; H, 8.72; Found: C, 66.03; H, 8.79. 

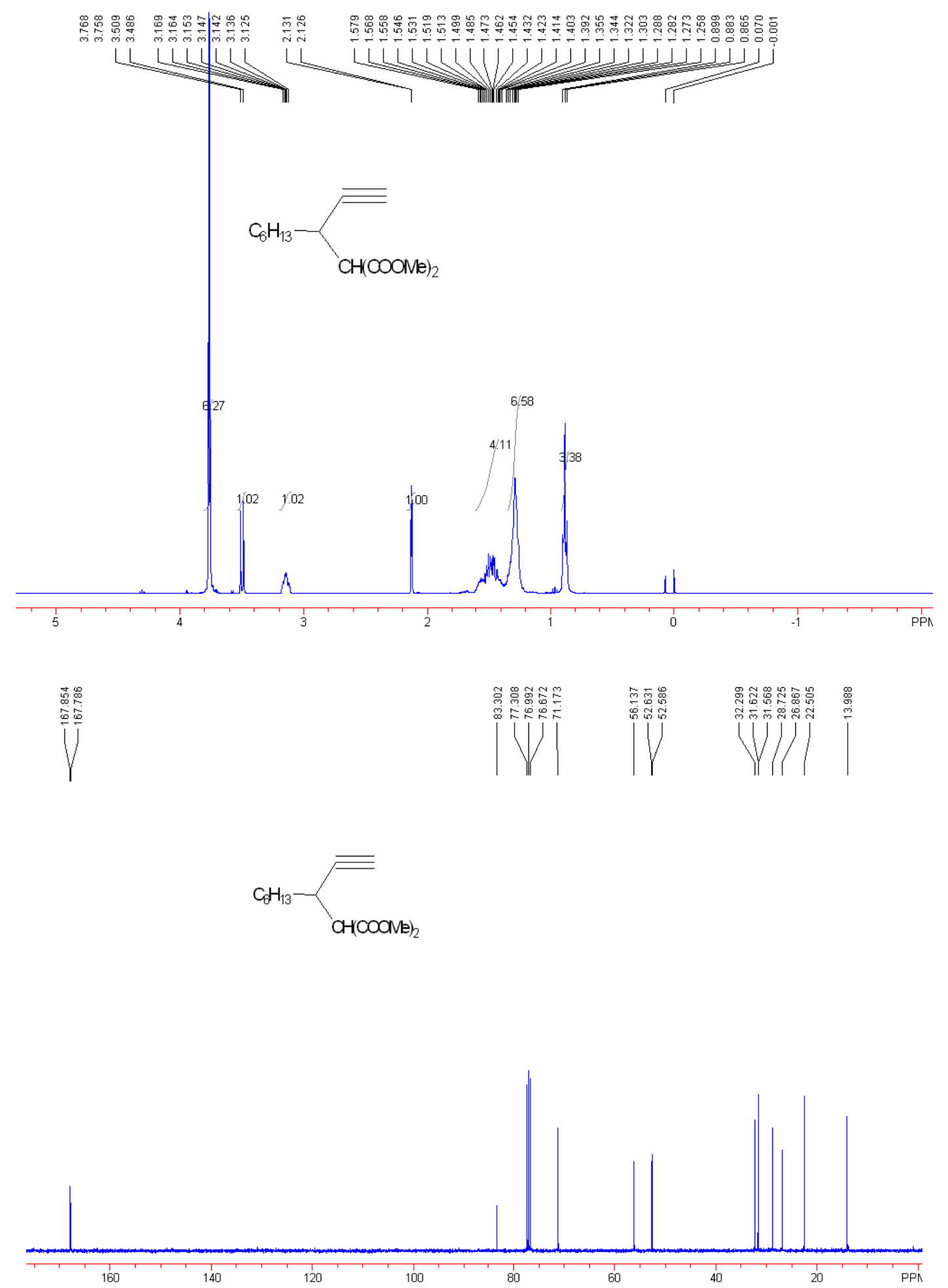